ventricular remodelling. These findings require further validation before clinical translation.

\section{BAS/BSCR free communication FC1 DIPEPTIDYL PEPTIDASE IV INHIBITORS LIMIT MYOCARDIAL
INFARCT SIZE IN A GLUCOSE-SENSITIVE MANNER} doi:10.1136/hrt.2010.205781.7

D J Hausenloy, A M Wynne, L Theodorou, M M Mocanu, D M Yellon. The Hatter Cardiovascular Institute, University College London, UK

Rationale The novel anti-diabetic agents, vildagliptin and sitagliptin, reduce blood glucose by augmenting endogenous levels of glucagonlike peptide (GLP-1), a substance which confers cardioprotection. They do this by inhibiting dipeptidyl peptidase (DPP) IV, the enzyme responsible for breaking down GLP-1. We hypothesised that DPPIV inhibitors might have cardioprotective effects.

Methodology Sprague-Dawley rats were given vildagliptin (oral gavage, $20 \mathrm{mg} / \mathrm{kg} /$ day), sitagliptin (oral gavage, $100 \mathrm{mg} / \mathrm{kg} /$ day), or control for 2 weeks. Excised hearts were then mounted on a Langendorff apparatus and perfused with buffer containing either $5 \mathrm{mmol} / \mathrm{l}$ or $11 \mathrm{mmol} / \mathrm{l}$ glucose and subjected to $35 \mathrm{~min}$ ischaemia/ 120 min reperfusion.

Results Vildagliptin pretreatment reduced myocardial infarct size in hearts perfused with buffer containing $11 \mathrm{mmol} / \mathrm{l}$ of glucose $(34.4 \% \pm 4.1 \%$ with vildagliptin vs $52.9 \% \pm 5.2 \%$ with control: $\mathrm{p}<0.05: \mathrm{N}>5 /$ group$)$ but not $5 \mathrm{mmol} / \mathrm{l}$ glucose $(53.2 \% \pm 4.8 \%$ with vildagliptin vs $52.6 \% \pm 7.2 \%$ with control: $\mathrm{p}>0.05: \mathrm{N}>5 /$ group). The infarct-limiting effects were abolished in the presence of exendin9-39 (a GLP-1 receptor antagonist) and H-89 (a PKA antagonist) $(61.5 \% \pm$ $3.3 \%$ with vildagliptin + exendin $9-39$ and $59.4 \% \pm 2.1 \%$ with vildagliptin $+\mathrm{H}-89$ vs $35.0 \% \pm 5.0 \%$ with vildagliptin+vehicle: $\mathrm{p}<0.05$ : $\mathrm{N}>5$ /group). Similarly, sitagliptin pretreatment reduced myocardial infarct size in hearts perfused with buffer containing $11 \mathrm{mmol} / \mathrm{l}$ of glucose $(29.5 \% \pm 5.1 \%$ with sitagliptin vs $52.9 \% \pm 5.2 \%$ with control: $\mathrm{p}<0.05: \mathrm{N}>5 /$ group) but not $5 \mathrm{mmol} / 1$ glucose $(44.4 \% \pm 8.8 \%$ with sitagliptin vs $52.6 \% \pm 7.2 \%$ with control: $\mathrm{p}>0.05: \mathrm{N}>5 /$ group). Again, the infarct-limiting effects were abolished in the presence of exendin9-39 $(63.6 \% \pm 5.5 \%$ with sitagliptin+exendin9-39 vs $30.1 \% \pm 3.4 \%$ with sitagliptin+vehicle: $\mathrm{p}<0.05: \mathrm{N}>5$ /group).

Conclusions Chronic treatment with the DPP-IV inhibitors reduced myocardial infarction via the GLP-1 receptor pathway and may also involve the PKA signalling pathway. Interestingly, this effect appears to be dependent on the blood glucose levels.

\section{FC2 ACTIVATING TRANSCRIPTION FACTOR 1 CO-REGULATES IRON, LIPID AND ANTI-INFLAMMATORY TARGET GENES TO DIRECT A NOVEL ATHEROPROTECTIVE HUMAN PLAQUE MACROPHAGE SUBSET}

doi:10.1136/hrt.2010.205781.8

${ }^{1} \mathrm{~J} J$ Boyle, ${ }^{1} \mathrm{M}$ Johns, ${ }^{1} \mathrm{~A}$ T Nguyen, ${ }^{1} \mathrm{~J} \mathrm{Yu},{ }^{2} \mathrm{~L}$ Game, ${ }^{2} \mathrm{D} \mathrm{J}$ Schaer, ${ }^{1} \mathrm{~J} \mathrm{C}$ Mason, ${ }^{1} \mathrm{D} O$ Haskard. ${ }^{1} \mathrm{NHLI}$ Cardiovascular Sciences, Imperial College London, UK; ${ }^{2} \mathrm{MRC}$ Clinical Sciences Centre, Imperial College London, UK

Rationale Monocytes entering tissues, including advanced atherosclerotic plaques, rapidly mature and adapt to their new microenvironment. Intraplaque haemorrhage promotes human atherosclerosis progression and destabilisation via a dual metabolic challenge: cholesterol-enriched erythrocyte membranes and haemiron. In human coronary culprit lesions, we recently described a novel macrophage subset (M-haem) with atheroprotective properties (IL-10high HO1high CD163high HLADRlow MPOlow 8ketoGuanosinelow).
Methodology We dissected the mechanism of M-haem differentiation by microarray, computational biology and gene manipulation in human primary macrophages and human coronary lesions.

Results Microarray analysis showed that M-haem cells were distinct from conventional M1 or M2 subsets. Using computational biology, we identified a simple transcriptional network motif with activating transcription factor 1 (ATF1) as a hub coinducing HO1, SOCS1 and NR1H2 (LXR- $\alpha$ ). Silencing RNA experiments showed that ATF1 induction was required for haem to upregulate HO-1 SOCS1 and NR1H2. Luciferase analysis confirmed that ATF1 transcriptionally activated both HO-1 and LXR. Luciferase deletion mutants indicated that the key ATF1-site in the HO-1 enhancer was distal $(-2.2 \mathrm{~kb}$ to $-4.9 \mathrm{~kb})$. Binding experiments showed that ATF1 bound to this sequence. ATF1 overexpression in human macrophages conferred the characteristics of $\mathrm{M}$-haem cells, including co-induction of $\mathrm{HO}-1, \mathrm{NR} 1 \mathrm{H} 2$, resistance to foam cell formation, increased survival and antioxidant protection.

Conclusions Our data define the molecular basis of the differentiation of M-haem, a novel atheroprotective macrophage subset. Our data indicate that redirection of macrophage phenotype in atherosclerosis progression is a modality appropriate for therapeutic development.

Acknowledgements We thank BHF for support; Y Tsuji, A Agarwal and P Tontonoz for plasmids.

\section{FC3 CHANGES IN NUCLEAR AND MITOCHONDRIAL DNA DAMAGE IN PRIMARY VASCULAR SMOOTH MUSCLE DERIVED CELLS AND TISSUE}

doi:10.1136/hrt.2010.205781.9

L A Hurst, J R Mercer, M R Bennett. Division of Cardiovascular Medicine, Department of Medicine, University of Cambridge, UK

Background All cells accumulate mitochondrial DNA (MtDNA) damage as they age. However, the tolerance of cells to these mutations remains unknown and has recently been implicated in the pathogenesis of cardiovascular disease. Similarly, while both cellular senescence and DNA damage response (DDR) markers (pATM and pH2AX) increase in vascular smooth muscle cells (VSMCs) with increasing disease severity, the effects of cellular ageing on DDR markers are unknown.

Methods We quantified the common MtDNA deletion (4977 bp), previously documented as a sign of plaque instability, using quantitative PCR ( $q$ PCR) in human carotid plaques $(n=10)$ or normal carotids $(n=7)$. DNA damage and DDR were examined in primary VSMCs of young (mean age 23 years) and older (mean age 60 years) patients using the COMET assay and immunocytochemistry for pATM/pH2AX, respectively.

Results The common mitochondrial deletion increased 1.25-fold in the plaques compared with the normal vessels $(p=0.04)$. In addition, sequencing identified a novel 5031 bp deletion variant, also 1.25 -fold higher in the plaques. VSMCs from older patients had increased DNA damage on COMET assay $(p=<0.0001)$ and greater abundance of DDR foci $(\mathrm{p}=<0.0001)$ than young patients, both basally and after treatment with the hydrogen peroxide analogue t-BHP.

Conclusions MtDNA damage, manifested as both increased levels of the common and a novel MtDNA deletion, increase in atherosclerosis. VSMC ageing is associated with increased nuclear DNA damage and DDR markers, implying that ageing compromises their ability to repair both nuclear and that MtDNA damage may promote premature senescence and atherosclerosis. 